This item was submitted to Loughborough's Research Repository by the author.

Items in Figshare are protected by copyright, with all rights reserved, unless otherwise indicated.

\title{
Social support and unsolicited advice in a bipolar disorder online forum
}

PLEASE CITE THE PUBLISHED VERSION

PUBLISHER

(c) SAGE Publications

VERSION

AM (Accepted Manuscript)

LICENCE

CC BY-NC-ND 4.0

\section{REPOSITORY RECORD}

Vayreda, Agnes, and Charles Antaki. 2019. "Social Support and Unsolicited Advice in a Bipolar Disorder Online Forum”. figshare. https://hdl.handle.net/2134/5437. 
This item was submitted to Loughborough's Institutional Repository (https://dspace.lboro.ac.uk/) by the author and is made available under the following Creative Commons Licence conditions.

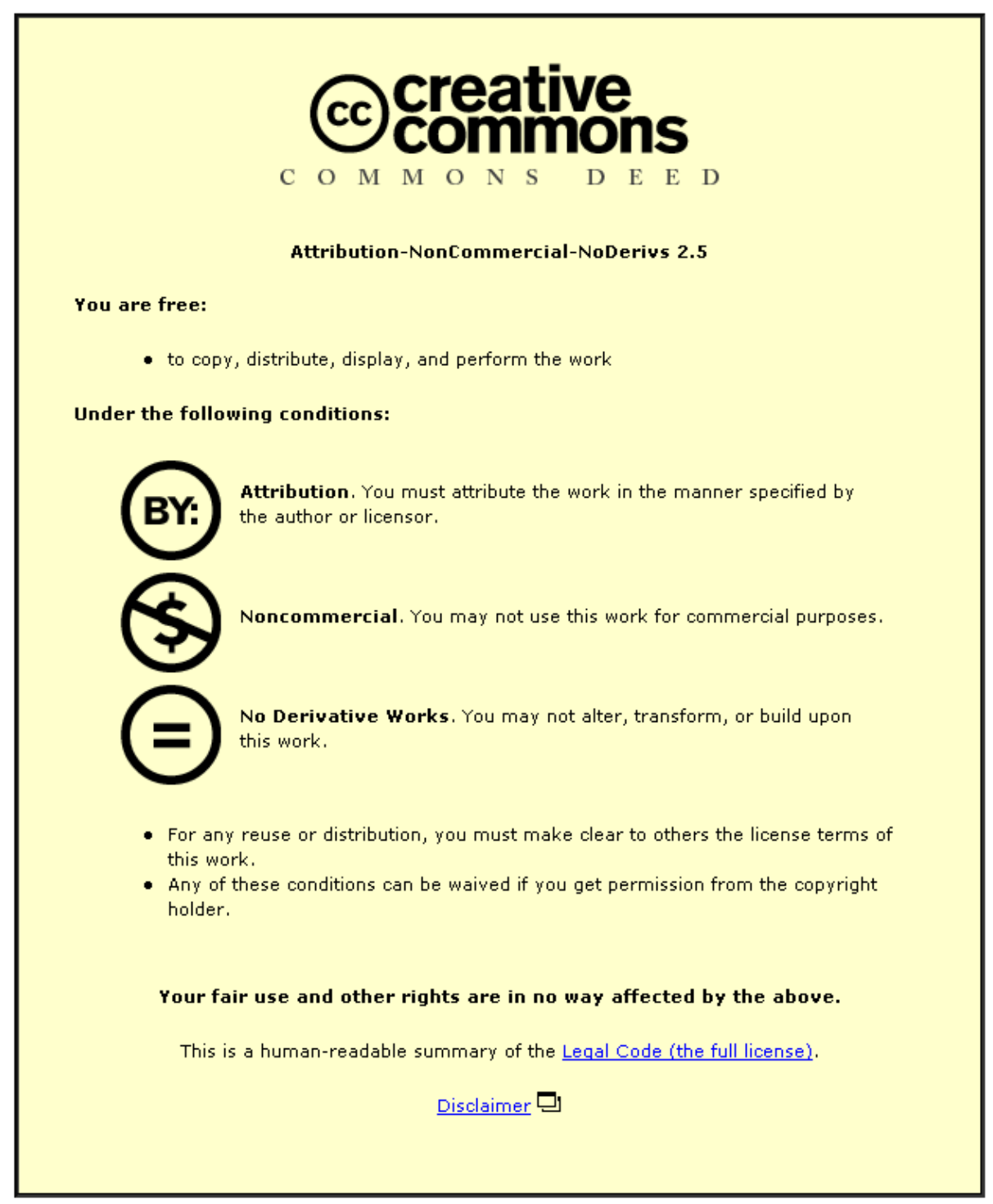

For the full text of this licence, please go to: http://creativecommons.org/licenses/by-nc-nd/2.5/ 
Short title: Bipolar Disorder Online Support

\title{
Social Support and Unsolicited Advice in an Bipolar Disorder Online Forum
}

Qualitative Health Research, Vol. 19, No. 7, 931-942 (2009)

\author{
Professor Agnès Vayreda \\ Estudis d'Humanitats \\ Universitat Oberta de Catalunya, \\ Av. Tibidabo, 39 \\ Barcelona 08035 \\ Spain. \\ E-mail: avayreda@uoc.edu \\ Professor Charles Antaki \\ Department of Social Sciences \\ Loughborough University \\ Loughborough \\ LE11 3TU \\ England. \\ E-mail: c.antaki@Lboro.ac.uk \\ [corresponding author]
}

Abstract 
How does a newly-diagnosed user get inducted into a forum dedicated to people suffering from bipolar disorder? Is their opening message "matched" by the forum's reply? We add to the literature on social support online by using Conversation Analysis (CA) to explore an apparent contradiction between a new user's first post and forum members' reply with ostensibly unsolicited advice. CA reveals the intimate relation between turns in sequence, an aspect of online communication largely ignored in existing work on social support. Seen from this perspective, giving unsolicited advice, although apparently a "mismatch", turns out to be a consequence of the open design of the new user's initial posting. We go on to speculate that such unsolicited advice might function at the ideological level to induct the new user into the mores of the group, not only in the kind of support it countenances giving, but into the very meaning of "bipolarity" itself.

Keywords: bipolar disorder; communication; conversation analysis; education, online; Internet; language; medical/health care discourse; medicalization; research, online; social support 
Online forums (or newsgroups) are internet locations in which people can read and post messages singly or in a developing "thread." One prime motive attributed to participation in such forums is the seeking (or offering) of social support (Walter \& Boyd, 2002) This motive, in its various kinds, has been studied through a variety of self-report methods, including questionnaires, diary studies, and interviews with users as well as through coding and content analysis (see Miller \& Slater, 2000, for an overview of the methods). Such studies have been valuable in exploring people's perceptions of the opportunities and limits that forums offer, and in understanding users' expressed motivations for using forums (Núñez, Gálvez \& Vayreda, 2002). But the methods so far described do not capture the ways in which users actually seek or offer support in the detailed design and sequence of their posts in the forum.

We want to explore the pivotal moment when a user announces themselves as new, and principally qualified member of a group: what the features of that turn are, and what are the features of the turns that move into the space that that opening turn sets up. As such actions as introducing oneself into a group must always have a local impact in specific groups, with specific characteristics, agendas and customs, we need to focus on a given group: here, a group offering support to sufferers of bipolar disorder.

\section{Bipolar Disorder Support Group}

The website (<http://bipolarweb.com>) that hosts our chosen forum disseminates information about bipolar disorder (BD) under headings such as "symptoms", "classification", "treatments", and "psychotherapy". The greater part of the information on the site is medical, and the site as a whole tends to the bio-medical account of BD consistent with the classification of BD by the international Clasificación Estadística Internacional de Enfermedades y otros Problemas de Salud, and the American Psychological Association's Diagnostic and Statistical Manual of Mental Disorders (American Psychological Association, 1994). The claim is that mood disorders associated with the condition (manic episodes, hypomania, depression and mixed moods) are caused by a pathological neuro-chemical imbalance. Elsewhere in mental-health circles there are, of course, other views of what BD is and how it might be treated, but, on this site, the preponderance of medically-based content, and ethnographic 
interviews with the site's founder (a woman who herself suffers from BD) confirms that this is the site's preferred orientation.

As well as providing information, the site also gives a voice to BD sufferers, in an open online forum. The forum is reserved for sufferers, and the friends and family (that is, mental health professionals are not encouraged to post messages). The site's founder moderates the forum, helped by an associate and some volunteer forum members, who also give technical support. Overall, the forum bears striking resemblances to online self-help groups pioneered in the USA (as described by Griffiths et al, 2006). The forum's portal states that "the site's administrators recommend that anyone affected by the disorder always seek professional advice. The messages here are a complement to, and not a substitute for, such advice". The majority of posters have been diagnosed with $\mathrm{BD}$ and are under some kind of pharmacological treatment; otherwise, they are friends or family. As well as the ebb and flow of ephemeral traffic, the active presence of a small number of regular posters over the five years of the site's existence has meant that a recognizably distinctive "culture" (in the sense proposed by Hine, 2000) has developed. Here, most posts receive at least one response, and the general tone is respectful, so long as users cleave to a biomedical account of the disorder.

\section{Conversation Analysis And Forum Postings.}

Now that we have a particular forum in sight, let us consider how best to analyse the pivotal moment of the new user's introduction into the group. This article is an exploration of what can be learnt from a close inspection of the design of turns in sequence. We want to identify how users exploit those aspects of the medium that correspond to, or are variants of, the turn-taking and turn-design rules that obtain in face-to-face interaction. The best candidate on offer for such an analysis is Conversation Analysis (CA), a perspective on talk-in-interaction which was precisely developed to explicate how people bring off social actions through their talk (for overviews of CA, see Hutchby \& Wooffitt, 1998; ten Have, 1999; and the original 1960s and 1970s lectures of its founder, Harvey Sacks, issued as Sacks, 1992). Although developed for synchronous human interaction, CA has been profitably applied to various aspects of computer-mediated communication, or CMC (see Herring, 2001, 2004, for overviews of CA's 
application along with other forms of discourse analysis). Within CMC the majority of CA work has been from the perspective of human-computer interaction (e.g., Frohlich, Drew, \& Monk 1994), with a developing strand of work on quasi-synchronous interaction such as chat-rooms (e.g., Garcia \& Jacobs, 1999). Our aim in this article is to build on recent applications of CA to the non-synchronous medium of the online forum (see Reed, 2001; Antaki, Ardèvol, Núñez, \& Vayreda, 2005).

To our knowledge, there is only one examination of forum postings that specifically uses concepts from CA to help understand the provision of social support - Lamerichs \& te Molder's (2003) study of how the users of a forum for people suffering depression discursively manage their identities. As Lamerichs and te Molder note, posting a message to a forum exposes the poster (as any utterance does for any interactant) to the challenges of coming across appropriately and accountably. In the case they study, it exposes the user to the challenge of displaying being "depressed" in appropriate ways, while also acting as a supportive forum user. Lamerichs and te Molder's concentration on the content of forum messages (principally, users' deployment of descriptions of emotions, and their invocation of different category identity labels), however, means that they pay comparatively scant attention to the ways in which users exploit the structural features of forums (the opportunities, for example, to initiate threads, to address given recipients, to respond selectively to elements of previous posts, and so on) to attend to accountability issues. In this article, we focus intensively on these sequential features of communication, for which Conversation Analysis provides a powerful conceptual apparatus.

\section{Sequential Placement Of The Message}

Perhaps the most central contribution that CA has made to the study of language in interaction is to display the power of the sequential placement of messages, or turns at talk (Heritage, 1984). The concepts of the adjacency pair and of sequential implicativeness (both in Schegloff \& Sacks, 1967) were among the earliest contributions to the developing armory of CA. In equating messages on asynchronous newsgroups with synchronous turns at face-to-face or telephone talk, we are following what is now an emerging thread in CA accounts of CMC; see, for example, Herring (1999) and, with specific reference to online forums, Reed (2001) and Antaki, Ardèvol, Núñez, \& Vayreda (2005). 
The basic idea is that any turn at talk (or any post) both enacts a certain action (or more than one action) and also opens up a given space for the next turn to perform a corresponding action (Sacks, Schegloff \& Jefferson, 1974). Thus to pose a question in a first post opens a space in which a post containing an answer to that question is in order; any departure from the prompt supply of that answer is taken to be significant. Equally, a subsequent turn can challenge the given meaning of the turn that precedes it; thus, for example, posting an open-class repair initiator (Drew 1997) like "What?!" after a clear question, challenges the appropriateness or pertinence of the question at that time, from that person, about that topic and so on. Each turn must be seen in its context. Now, researchers in CMC are already perfectly aware of the role of context: as Robinson \& Turner (2003, p 230) put it, “Changing the context of a message changes the meaning". But Robinson, in common with other non-CA analysts of internet communication, sees context as being provided by general, high-level factors: "it is important,” Robinson continues, "to consider both the content of the message and the nature of the relationship between the communicants to understand the effectiveness of social support." (Robinson \& Turner, 2003, p 230). But this undervalues the very local context of the particular sequence of posts (or turns) that surround any particular post.

This sequence is vital. The "relationship" beween communicants might only be inferred from what they actually do in their posts; and it is those posts themselves (we argue) that make the contexts for the posts that follow. As Heritage and Maynard put it: "utterances, turns of talk, and their subcomponents perform recognizable actions that are both context-shaped and context-renewing" (Heritage \& Maynard, 2006, p14). That was said in relation to spoken language, but is applicable to turns in an asynchronous medium such as an online forum (Antaki, Ardèvol, Núñez, \& Vayreda, 2005). One post shapes a space (makes a context for) the next, and the next occupies that space in its own way, and makes another space in its turn. It is this logic that will allow us to see how users actually realise such higher-level analytical concepts as social suppport and the particular hypothesis that users' requirments ought to be matched by what a support group offers. Let us turn to a brief review of those issues now.

\section{Social Support And The Match Between User's Request And Its Reply}


The great variety of potential sources of support on the web make it a promising place for a user needing help to look. Indeed, this variety forms the cornerstone of the influential, and now venerable, optimal matching theory of Cutrona and colleagues (Cutrona \& Russell 1990; Cutrona \& Suhr 1992). The online user can choose from a universe of experts and find a group whose experience specifically matches her or his own; something much less easy in the face-to-face world. This brings in its wake a theoretical observation specifically about online social support - that it is particularly good at matching what is provided to the user's needs. From a burgeoning literature, we pick out some illustrative quantitative studies: for example, that a coding study of one online forum for people with disabilities (Braithwaite, Waldron \& Finn, 1999) shows that emotional and informational support accounts for the majority of messages; or that "network" support is at almost equal weight, according to another coding study (by Coulson, Buchanan, \& Aubeeluck 2007; see also Coulson 2005; Coulson \& Knibb, 2007). Users do say that they go to forums to minimise the mismatch between what they want and what they might get from such other sources as friends, family and others in their immediate environment (Robinson \& Turner 2003; Walther \& Boyd, 2003). Turner, Grube \& Meyers (2001), in another empirical test, did find support for the optimal matching hypothesis, in that individuals lacking social support in the real world were more likely to turn to online alternatives as a means for social support.

Of course this is only, as we say, an illustrative dip into the wide literature on online support. But, in spite of some inconsistent evidence and a need for refinement (see, for example, Goldsmith's thoughtful reflections on the model; Goldsmith, 2004) it does suggest that there is convergence between users' needs and online sites' provision. Nevertheless, as we hinted at the start of this article, the evidence on which the matching hypothesis claims are based, strong as it is (from interviews, questionnaires, content and thematic analysis and so on), does not reveal the detailed practices by which any given request for help is made and redeemed. Yet social support must be a matter of displayed interaction; it must be made manifest in the actual postings of the forum. The question that we want our investigation to ask, then, is: what does online support look like in its detailed exchange, at the pivotal point where the user first comes on the scene? 


\section{Matching The New User's Initial Post}

One pivotal place where such support ought to be visible is the induction of a new member to the group. Even more especially, the phenomenon ought to be at its sharpest when the new user specifically announces themselves as being exactly the right "identity" for the group (in our case, someone with bipolar disorder, wanting help). But those who do qualify as the "target" group - those who actually have been diagnosed with BD - are, along with family and friends, the raison d'etre of the forum's existence. Our data, then, will be first posts from people self-identifying as diagnosed with BD. Another, more interactional importance of at initial posts is that they set a high premium on responses; an unanswered new user might be discouraged from returning, and, conversely, the response presents the new user with his or her first (direct) evidence of whether the group suits, and of what it can offer. Indeed, our ethnographic interviews with the site's founder and moderator suggests that this is a concern for the forum, at least with regard to users who are not obviously antipathetic to the site's biomedical orientation.

\section{Method}

We looked at the kind of interactional features identified by Conversation Analysis. We intended to explicate how they are exploited in a given environment, so an intensive approach with a small number of cases was in order. This intensive logic is familiar from Sacks' early lectures (Sacks, 1992) and is well established in CA; see, for example, its defense by Schegloff (1987), and Schegloff's use of the approach to exemplify what CA reveals that a more impressionistic analysis would not (Schegloff, 1988). For a more general extended defense of small case studies in CA, see Hutchby \& Woofffitt (1998, chapter 5). CA was originally developed for the analysis of spoken language, but is now finding application in computer-mediated communication (as we noted above). We should add a note on working with Spanishlanguage texts. CA has, over the years, developed an apparatus that has proved fruitful well beyond the varieties of English first studied by its North American founders, its early British adherents, and its growing community of European researchers. Important work in CA has been done in languages as distinct from English as Japanese (e.g., Ford \& Mori, 1994), Finnish, (e.g., Sorjonen, 1996) and Korean (Kim, 1999). One of the authors of this article is a native Spanish speaker, and work was done on the 
Spanish-language originals though we report in the text only our English translations, for reasons of confidentiality (see below).

Data

Our data came from a forum which is part of a public, web-based Spanish-language site devoted to the support of people with a diagnosis of bipolar disorder, and their friends and family. The portal $<$ http://bipolarweb.com> gives free access to, among other sub-sites ("experts", "the Press" and "my history"), a newsgroup ("foro") at <http://bipolarweb.com/normas1.htm>. Once at the forum, users can read or post a message. No identification is necessary to read the messages, but one has to supply a nickname to post either a new entry or a response to an existing one; this, however, is subject to no validation, and one simply types in a name and proceeds to post under it. However, once posted, a message might be deleted by the moderator. In any case, messages (and their threads) are routinely taken off after about two months.

The issue of gaining informed consent from forum users is a matter of much debate in the literature, with articles in this journal making significant contribution (e.g., Flicker, Haans \& Harvey, 2004). Central to the debate is the question of whether to conceive of forums as being public or private spaces. Some researchers claim that the defining characteristic of a public space on the internet is that access to it be open (Walther, 2002), on the basis that users are aware that their posted information is available to all comers. Other researchers query whether all users do, in fact, share the same understandings of what open access means (Elgesem, 2002) and treat the space as private, or semiprivate. This affects researchers as much as users: for example, Sharf (1999) in researching a user group for cancer sufferers, expressed the concern that it was likely that only regular users were aware that their messages were objects of scrutiny, in spite of Sharf's repeated announcements of the project underway (Sharf, 1999. p 249).

Bipolar web does advertise itself as a public forum, but nevertheless, in an effort to maximize the users' awareness of our access to their data, we followed this procedure: before starting our recording of forum activity, we contacted the Bipolar website controller (the founder of the site) to apprise her of our 
interests and intentions, and to seek permission for going further. The controller herself posted a prominent announcement on the site explaining our research interests, and alerting users to the fact that we would have access to their messages. This announcement generated no complaints or queries. Later, about half-way through our project, we posted (with the controller's permission) another message reminding users of our presence, and of the anonymity and confidentiality of any data we collected. This generated a small number of approving replies, and no complaints.

In spite of these measures, we acknowledge that impression that only the more active and frequent users of the forum might have been conscious of our presence, a familiar situation to other researchers in similar projects (e.g., Sharf, 1999). This concern required us to be especially vigilant in maintaining users' anonymity. Note that users to the Bipolar site post messages anonymously, via nicknames; but in reporting their messages here, we have introduced another security layer by replacing those nicknames with pseudonymous ones respecting the originals' general style and (if marked) gender. To still further protect any possible trail back to even to the original users' nicknames, we have only reported our English translations of the text of the quotes so that they cannot easily be traced via an online search.

\section{Selection Of Initial Posts}

Our interest is in the pivotal moment in which a new member appears, so the criterion for inclusion is merely that the post identify the user as recently being diagnosed with BD. Note that we do not include posts from existing users or from a new user but do not claim to have a diagnosis of BD (e.g., posts which are from casual enquirers about the nature of the forum, or who are family members, and so on). Over the period 27 March 2008 to 14 May 2008 we found 14 initial posts that fitted our criterion, so, although such posts are pivotal in the induction of new members, they are not statistically frequent in the overall traffic of the site (which received 1960 posts over the same period).

We start with a typical first post of the kind we have in mind. Note that the material in bold is in the subject line; the word or phrase immediately after, also in bold, is the user's nickname. Thus in Example 1 below, the subject line is "Recently come to bipolarity", posted by a user whose nickname is 
pseudonymized here as "mikokana". Dates have been removed for greater anonymity. The clock time is, according to a number of warnings posted by the site's administrators, not reliable, but the sequential placement and indentation of posts is (lower position and greater indentation meaning commentary on the immediately-above post; a return to the left margin meaning a return to commentary on the original post). We have tried to capture the idiomatic sense of the words, and have used English counterparts for the non-standard uses of grammar and punctuation in the original Spanish.

\section{Example 1: mikokana}

\section{" Recently come to bipolarity" - mikokana -}

[date] 18:00 Just recently I've been diagnosed with it, which left me gobsmacked, I hadn't a clue what "bipolarity" meant it explains lots of things in my life but it's going to be hard getting used to it... It'd be great if someone could share this first stage of acceptance with me, or tell me how they got through it. Because my initial reaction is a "shit - no way am I bipolar".

This posting has the basic feature of our search criterion: that the original poster is new, and has recently been diagnosed as having BD Here is the first response, from "Lin":

Example 1a: mikokana (continued).

Welcome. Acceptance is a process. but the quicker you manage it, the better you'll cope with the illness, you have to learn to live with it, follow the treatment religiously, appointments with your psychiatrist, sleep well.... - Lin [date] 18:48 the illness can be lived with. it's tough at first, but there's nothing for it but for us to put our best foot forward. Regards.

\section{Analysis}

As we go on, we shall add more examples but let us outline here what we find are the bare bones of this initial message and its response, which we shall see replicated in the rest of our sample. The key features of initial messages were that the user had just been diagnosed with BP, or just come to realise it; was unhappy / worried / upset; and would like (vaguely specified) help. The key features of the response were 
that the responder empathised and gave unsolicited advice. That is to say: in the original message we shall of course (as that is the criterion for selection) see the user tell of their diagnosis. The we discover that the user describes his/her situation as unhappy in some way, and then goes on to pose a generally-worded request for some kind of help - but, we notice, not advice. The post might contain other things, but these three features seem to be routine.

In the response, we find the forum member making use of two basic features (usually in this order, but not necessarily)- they identify themselves as having BD or otherwise display some form of emotional support or rapport with the new member; and - here we point up our major finding - they offer advice (which had not been asked for). They might also do other things, but these are not found in every response. There are deviant cases in which the three basic features do not appear in the responses, but inspection reveals that if they are absent, then it is because of systematic differences in the original posting, and we shall analyze this deviancy later.

In the analysis to follow, we shall be first making some observations about the original posting, taking the opportunity to spell out the general style of argument in Conversation Analysis, then analyze the practices we see in the responses. At the end of the article, we shall spend time in a discussion of the asymmetry between the advice-giving of the responses and the apparent lack of a warrant to do so in the original post - an observation that can only be made by analysing posts in sequence, and would be lost to a less sensitive form of content or thematic analysis. There is, in contrast to the matching hypothesis of Cutrona and colleagues (Cutrona \& Russell 1990; Cutrona \& Suhr 1992) and later researchers, a mismatch, we shall see, between what the newcomer apparently wants, and what the response from the forum provide. But, as we shall argue, the mismatch is in part a consequence of the communicative contingencies that the new user has to work under in posting for the first time, and in part a demonstration of the forum's strong commitment to a certain view of the bipolar disorder which is its subject.

\section{The Original Post And Its Take-Up}

As we know - as it is the criterion for selection - the user tells of their new diagnosis of BD. But we noticed, in our sample, three things about how that telling is done, which are consequential for the 
space that is opened up for the next turn - that is to say, for what the response ought to look like. One of CA's insights that we are pursuing in this article is that posts happen in sequence: one turn stakes a claim, and sets the parameters for the next. Let us see, then, how "mikokana" in Example 1 designed her / his post as a first turn in a dialogue, and add in examples from other messages in our small corpus (space does not allow us to reproduce all the examples).

a. News. The user states their BD status not in a way that would be glossed as "mentioned in passing", nor "alluded to" nor otherwise embedded pragmatically in the message, for inference and drawing out: it is plainly displayed as a news announcement (Heritage 1984b). That is, it is presented explicitly as a revelation - information recently revealed or discovered ('just recently', in Example 1, and in similar terms in other messages, e.g., 'a few weeks ago', "they just diagnosed me as bipolar last Wednesday'; "my diagnosis was confirmed yesterday"), or otherwise newly live or operative in the user's life ("my family can't stand me .. they think I'm bipolar"; "I've come to realise that I'm pretty ill, I have recurrent thoughts about suicide") . That has the consequence of providing for its immediate reception as news by others - in other words, it permits (or encourages) a response to the post in terms of a straightforward news receipt. b. Unhappiness. The new user adds a distinct emotional overlay to this news, almost always negative (save in deviant cases which we detail later) and sharpened by extreme case formulations (Pomerantz, 1986): "'I was gobsmacked" in Example 1, and "I feel like a space alien", "I can't stand myself", "it's making my head spin", "it's horrific", "I'm trying to lead a normal life, but it's impossible", elsewhere. Pomerantz has shown (1986) that such extreme-case formulations generally appear in an account of trouble and complaint; and, as Edwards (2000) argues, their very brittleness to disconfirmation (the user was not literally gobsmacked, is not really a space alien and so forth) indexes the irrelevance of any easy reassurance - the descriptions tell what is essentially the case about the user's (horrible) experience. The appropriate news receipt, then, is one that recognises horror.

c. Help. The user asks for some kind of help; but this is not cast as a request for advice. Significantly, it is usually for something vague or comparatively undemanding. In Example 1, the user says: "It'd be great if someone could share this first stage of acceptance with me, or tell me how they got through it", and other 
examples are "I'd be interested to know if are many others like me"; "I'd like to learn all about this illness"; "are there any therapy support groups in Barcelona?"; "am I nuts or just worthless?". Such requests require comparatively little from the next poster: they index what Curl and Drew (2008) calls the "low contingency" of the request to the possible provider (in Curl and Drew's case, a doctor; here, any forum member). The user is wanting something neither costly nor difficult to supply. The low bar eases the obligation on the potential responder, so makes a response more likely.

These three features, which seem to be the default characteristics of all the initiating postings in our sample (limited, of course, to posts which announce that the user has BD), add up to this: that the new user offers the forum the opportunity to treat the post as a news item, reporting an identity (BDdiagnosed) of automatic relevance to, and wanting sympathetic response from, this forum; if they give any more, then it need be nothing too demanding - information, "sharing" and so on. This "ticket of entry" as Sacks (1992, p257-258) calls it, is priced low, and bids to get the new user into the group as a fullyqualified member. Now: how does the forum treat it?

\section{The Response}

We can start by seeing how Example 1 was dealt with. Recall that the new user ("mikokana") was "left gobsmacked" by his/her recent diagnosis, and would like it "if someone could share this first stage of acceptance with me, or tell me how they got through it". Recall the response from "Lin":

Example 1: mikokana (repeat)

\section{Welcome. Acceptance is a process. but the quicker you manage it, the better you'll cope with the illness, you have to learn to live with it, follow the treatment religiously, appointments with your psychiatrist, sleep well.... - Lin [date] 18:48 the illness can be lived with. it's tough at first, but there's nothing for it but for us to put our best foot forward. Regards.}

The ticket of entry has been redeemed: the new user is welcomed. In fact that welcome seems to be optional, and is not a regular feature of the responses. It the more regular material that interests us. Recall that we outlined the features as having these elements: the respondent affiliates with the initiator by 
disclosing that they are bipolar too or makes some other empathetic gesture; and they offer advice. In this post the self-identification as also being diagnosed with BD is rather indirect (it is plainly asserted in others, as we will see) by the use of the 1st person plural in lines 7 and 8 , which we render idiomatically in English as "there's nothing for it but for us to put our best foot forward". The "us" can only be those who suffer the illness. This group affiliation is made a little more empathic with the sympathetic "it's tough at first".

Now we turn to our main finding, the unsolicited advice. The first format that Lin, the responding forum member, uses is of generalized information ("acceptance is a process") which is a usefully impersonal format for advice about sensitive matters, especially about health; see, for example, Silverman's pioneering work on advice-as-information (Silverman, 1997) in counsellors' dealings with clients in an HIV clinic, and Heritage and Sefi's records of community health visitors' interactions with new mothers (1992).The next format of advice introduces the pronoun "you" in a conditional ("the quicker you manage it..."), but this is ambiguously either mikokana in particular or "you" in general. Then Lin uses the most direct form of advice, the imperative - "you have to learn to live with it" as the start of a series of instructions (not always standardly-formatted in the original Spanish).

At this point we can make a simple list of the formats of advice we see in these responses, set out in a heuristic table, with examples:

Table 1 about here

We don't intend to pursue the pragmatic differences between these formats of advice giving, suggestive though the differences among them look; what we want to signal is that here, in the body of the response (often, as in Lin's example above) accounting for the greater part of its substance), the new user is being told what to do, even though what he/she said she wanted was something vaguer. We shall return to the asymmetry (or, as we shall see, ostensible asymmetry) at the end of this article, but first we shall go through another pair of initial post and response, to populate the story with another example. 
Example 2: Kanku

"TELL ME WHAT'S HAPPENING TO ME" - KANKU - [date] 22:27

Hi.. I live in Venezuela, in an eastern state or province .. my life is a mess .. I'm 33 years old and I've edone [sic] nothing with my life .. materially I've got nothing [...] 9 years ago I went to a sychiatrist [sic] and was told that I was a manic depressive .. they gave me some pills I can't recall I took them like for a week .. after that I forget .. I've stolen money from my family, and spent it on going out, prostitutes and rubbish [...] I feel like rash ... I'm alone, my family can't stand me they think I'm bipolar.. am I nuts or just worthless?

my e-mail is: [anonymized]

Look you're not well and need professional help. If I were you I'd go see a psychiatrist without hesitation. He'd give you a diagnosis and start to give you the treatment you need. Stop beating up on yourself and get going.Good luck (no text) - LaPati - [date]

Re: TELL ME WHAT'S HAPPENING TO ME - spefra - [date] what's going on is that you have to make peace with yourself. make some short-term goals you can achieve. cos from what you write you seem intelligent I'm sure you know what you need to do and how. little by little you'll start to feel fulfilled and happy and that'll certainly make you appreciate what you've got and you'll not feel the slightest temptation to chuck it all away again.

don't look back. the past is the past.

good luck

regards

Once again we see the three main keynote features in the original post: the poster is unhappy (and we have skipped the more distressing material) and both introduces the post, and signs it off with a 
request for rather general help ("Tell me what's going on, and am I nuts or just worthless?"). What is noteworthy is the user's apparently long history of bipolarity - s/he was diagnosed with it nine years ago. This is different from the canonical way the new user presents themselves, as having been diagnosed just recently. But notice that Kanku nevertheless manages to make the issue of bipolarity newsworthy at the end of the message: his family thinks he's bipolar. Coming here, at the end of the post this makes his diagnosis - and his query about his madness - the most obvious theme for a potential respondents to pick up on. Material at the end of a turn at talk is most available for commentary (Sacks, 1987; see Antaki, Ardèvol, Núñez, \& Vayreda (2005) for a discussion of this CA principle in online forums).

Consider now the two responses. We note just in passing that they do show some degree of empathy (not, perhaps, a great deal, but there in such formulas as "you seem intelligent and I'm sure you know what to do and how". We concentrate on the advice which, again, was not explicitly solicited (recall that Kanku ostensibly wanted to know whether he/she was "nuts or just worthless"). Nothing could be more directive than "LaPati's" first line (and recall that this is in her subject line, there is no body of text to her message; it is visible without the user having to read further): "Look you're not well and need professional help". There is a strong element of "tough love" in her message, encapsulated in the advice to "stop beating up on yourself and get going"; at first sight, this seems wholly disaffiliative with Kanku's request. The same can be said for the second response, from "spefra": again we see the familiar formats of advice giving (the modal expression "you have to..."; the directives "make..." and "don't.."; the axiomatic pronouncement ("the past is the past"). We could dwell still more on the advice we see in these responses. but recall that it is all unsolicited. How then does this square with the "matching hypothesis", which predicts that successful forums (as this one is) ought to provide what the user wants? Before we turn to that, let us just clean up some hanging issues - cases where the first-time user does not get unsolicited advice.

\section{Deviant Cases}

Not every announcement of a diagnosis of bipolar disorder was met with unsolicited advice; but where it was not, there turned out to be very interesting features in the announcement which seemed to 
have protected the user from that kind of response. Analysis of "deviant cases", where the general pattern is not the case is useful for two reasons - it forces one to rethink the rule, if one can't see a good reason why it was not followed in this case (in CA, the earliest and prototypical example of this was in Schegloff's use of one deviant case, out of a very large number, to rethink the rule for US telephone users' openings; Schegloff, 1968); or, as we shall show here, the deviant case reveals initially-unsuspected aspects of the case that explain the deviancy.

\section{Deviant Case Type 1: Response Gives Information, But No Advice}

We start with the most radical case: - the new user announces they have recently been diagnosed with $\mathrm{BD}$; but the responses (of which he / she receives two) give no advice. Why might this be?

\section{Example 3: xinon}

help please - xinon - [date] 20:51 I'm 23 years old and a few weeks ago they diagnosed me as bipolar and I've been under the psychologists since I was 18. in total I'll have 2 years of national insurance (I worked and took sick leave), soon I'm having a medical assessment and my worry is if they leave me with nothing I don't know what'll become of me and it's just making my head spin please someone help me do I have the right to any incapacity benefit or dole? I haven't got a clue

depending on the degree of disability they assess you at, very little I'm afraid. Ask flordeluna (no text) - mer cedes- [date] 22:04

\footnotetext{
Re: as far as I know, some laws have recently changed ... I mean with regard to medical assessments not incapacity benefit - happi - [date] 23:05 previously you needed 18 months out, extendable to 24 months and that got you the assessment. they'd count the previous five years as contributing toward a pension. I've no idea about how non-contributory pensions have changed, as far as I know, but to be honest I never paid much mind and I don't want to say something that might be wrong anyway as mercedes says, ask flordeluna, she's sure to be able to answer your question
} 
There is advice, in the suggestion that the new user contact another member, "flordeluna". But as flordeluna's e-mail address is not given, the new user either has to find a way of contacting flordeluna via his/her posts elsewhere, or wait until she/he reads it, and takes the initiative to come in and help the new user. What features of the original message, then, delete the opportunity for forum members to respond with advice? The answer must lie in the specificity of the new user's problem: he/she sets out a legal position, and explicitly asks whether he/she has a right to welfare payments. What s/he gets is not even set out as legal advice; it is cast as general information (from "mercedes") or personal experience (from "happi"). This is to be contrasted with the default case, where advice comes when what is asked for is more general.

\section{Deviant Case Type 2: Response Gives Empathy, But No Advice.}

Here again there is something about the initial post, although it announces a diagnosis of bipolarity, receives no advice. In the first example below, although three forum members post a reply, only one of them bears a message at all, and that is essentially empathic.

Example 4: Ade

Hi, good evening, I've got something to tell you all - Ade - [date] 22:59. Yesterday the diagnosis was confirmed, - BD. which I knew.

This afternoon the shrink was asking me a load of stuff and was back to saying the BD thing definitively. It's been a relief finding out, because now a lot of things are clearer to me.

I'm really excited

Kisses. and happiness.

- Magda - [date] 10:32

Re: Hi, I'm delighted that you're taking it in good heart and you're so positive - Ami - [date] 23:20

- emlach - [date] 07:47 
Thanks, (no text) - Ade - [date] 10:06

The absence of advice here is provided for by two features of Ade's post. For one thing, rather than casting the diagnosis of $\mathrm{BD}$ as a negative experience, Ade makes it something to celebrate. For another, there is no request for any reply. It might be that Ade is already known to the forum, and not a new user; but still, s/he had the opportunity to announce the diagnosis in just the negative terms that we saw in the body of the article. Not doing so seems to have made a response in terms of advice inappropriate. Indeed, two forum members ("Magda" and "emlach") merely post the minimal entry (their nickname), apparently as a "nod" or show of solidarity. Celebration of the diagnosis warrants little more, apparently. Here is another example of this withholding of advice:

\section{Example 5: Stella}

"nothing, really" - stella - [date] 14:40 Hi everyone I'm bipolar and I don't feel at all unwell I've already been through some very powerful manic episodes but now I lead a normal life, I'm only bad tempered and depressed occasionally which I try tocontrol it's all in the mind and in the pills they give you and I can't stop taking them because if I do everything goes to pieces.

Anyway don't worry whenever I'm depressed I think ofothers who are worse off and have very serious illnesses.

Re: if you look back there's always someone worse off than you and if that makes you feel better all the better go for it all's fair in love and war kisses (no text) - plaf - [date] 19:56

The same thing happened to me: although I've had some very bad episodes, I know that there are people much worse off, with illnesses with a worse prognosis. It's not much, comfrot, but that's how it is. We can live a 'normal' life. (no text) - Jennifer - [date] 18:14 
Example 5 has the same features as example 4: the celebration is rather muted (stella knows that there are "others who are people worse off"), but she is not complaining. What she gets in response from plaf is perhaps on the margins of advice ("if that makes you feel better then go for it",) but comes across as does Jennifer's message (with its direct echo of "people worse off") - as empathetic support and

affirmation. In other words, unlike the cases where the diagnosis was bad news, if the user casts it as good or at least bearable news, s/he gets a response that matches up to her/his post. But, as we have seen in the main line of the analysis, a bad news diagnosis gets unsolicited advice. In the last section we examine this further.

\section{Discussion: The Mismatch And Its Sequential Explication}

The aim of this article was to shed light on the interactive nature of social support in an online social support forum - in our case, a forum that supports people with bipolar $\underline{\text { disorder, }}$ and their family members. We chose as our specific target the pivotal interaction between newly diagnosed user and the initial responses to their message. We wanted to use Conversation Analysis (CA) to bring to light the interactional practices that emerge in the exchange between original message and its response. We had in mind to explore just how it was that social support is played out, with the specific hypothesis in mind, following Cutrona and colleagues' "matching" hypothesis (Cutrona \& Russell 1990; Cutrona \& Suhr 1992) in support forums, that there should be a close relation between a new user's stated requirements and what the forum offered in return.

What we found was that there is a regular set of features that is available both to new user and to those who respond to her or his initial presenting message. In the analysis, we delineated the basic elements, but here we want to pick out one major feature from our findings: that there was an apparent mismatch between what the new user wanted and what the forum gave. The forum responses privileged advice, even though the user wanted (or claimed to want) something much less directive (and although research suggests that advice is not always welcome, at least in principle, as Cutrona \& Suhr 1994 themselves report) . For example, users wanted accounts of others' experience (e.g.,: "It'd be great if someone could share this first stage of acceptance with me, or tell me how they got through it"), 
reassurance (e.g.,: "I'd be interested to know if are many others like me"; "tell me what's happening to me....am I nuts or just worthless?") or basic information (e.g.,: "I'd like to learn all about this illness"; "are there any therapy support groups in Barcelona?"). What they got was advice: in imperatives, modals, axioms and explicit warnings as to what might happen if they didn't take such-and-such a course of action.

At first sight, this seems to be a simple contradiction of the matching hypothesis, and a victory for unappreciated advice. It seems that the user is not getting what they want. But a consideration of the relationship between the two messages reveals something subtler and more interesting. The exchange, although not a match in terms of content, works. What is going on, we would say, is a negotiation between a new user who opens the bidding low, and a responder (the forum) which takes the open opportunity to lay its own cards on the table. The design of the two messages as a sequence is complementary - a reading just of the messages' content would be misleading. The actions complement each other to fulfil functions which we hinted at in the analysis, and to which we return now. The matching hypothesis, then, is too static : it needn't be the case (although it might sometimes happen) that the new user approach a given site with a clear idea of what is on offer; or indeed that they have the right to receive it.

The low bid allows the forum (personified by any one responder) many ways to respond. Advice giving is by definition directive; in directing the new user, the forum displays the authority of science, and the hard-won wisdom of experience. The new user is introduced into the culture of the group in the most unmistakeable way - s/he doesn't merely hear existing member's narratives, or receive generalized information, but is told what to do. If the new user accepts the advice, they commit themselves to a distinctive perspective on their illness.

The didactic function of the forum's treatment of first-timers comes out in the clearest possible way in the last example we shall cite, which condenses the giving of ideologically-tendentious advice into one short, sharp instruction:

Example 6: Perdida 
"hi" - perdida - [date] 09:01

hi i need help please i think i'm bipolar I can't stand myself sometimes i don wanna do anything and all of a sudden i feel i own the world and i wanna do it all but that doesn't last long and then i fall over again i wanna sleep the whole time tell me where i can go or what i can do i begg you ive also begged my family and friends and they tell me im nuts and i'll get over it

\section{Get an appointment with a psychiatrist and he/she will tell you what's wrong - mercedes- [date]} 22:06

The initial post has all the hallmarks of the desperate user - except the actual, medically warranted diagnosis of being "officially" bipolar. And the advice she gets is simply and directly to go to a psychiatrist and get that warrant; the implication is that only then will her doubts be settled.

That instruction to go straight to the psychiatrist shows, in microcosm, the ideology of the forum. It crystallizes the site's motivating spirit, visible from its title page, and on which we have already commented : that only one account of bipolar disorder will be countenanced, and that is the biomedical. No time is afforded to any consideration of the user's symptoms or circumstances. For the forum, diagnosis must be in the hands of the psychiatric profession, the ultimate authority on the illness and its treatment; the forum offers support, information and, indeed, advice, only on that basis. The possibly rather brutal response to "perdida" uses the wide-open space of her request ("tell me where i can go or what i can do") to tell her - and reiterate, for the exiting members - that the properly authorized diagnosis must come first. The structure of open request allows the response to choose its path. And that path is biomedical diagnosis. Once she has that, then she can enter the community of forum users and the site's resources will be at her disposal. 


\section{References}

Antaki, C., Ardèvol, E., Núñez, F., \& Vayreda, A. (2005)"For she who knows who she is": Managing accountability in online forum messages. Journal of Computer-Mediated Communication, 11(1). http://jcmc.indiana.edu/vol11/issue1/antaki.html

American Psychiatric Association (1994) DSM-IV: Diagnostic \& Statistical Manual of Mental Disorders. Arlington, VA: American Psychiatric Association.

Braithwaite, D. O., Waldron V. R., \& Finn, J. (1999) Communication of Social Support in ComputerMediated Groups for People With Disabilities Health Communication, 11(2),123-151

Coulson N. S., (2005) Receiving social support online: An analysis of a computer-mediated support group for individuals living with Irritable Bowel Syndrome. CyberPsychology and Behavior, 8(6), 580-584.

Coulson N. S. \& Knibb R. C. (2007) Coping with food allergy: exploring the role of the online support group. CyberPsychology and Behavior; 10(1), 147-150.

Coulson, N. S., Buchanan, H. \& Aubeeluck, A. (2007) Social support in cyberspace: A content analysis of communication within a Huntington's Disease online support group. Patient Education \& Counseling, 68(2), 173-178.

Cutrona, C. E. (1996). Social support in couples; Marriage as a resource in times of stress. Thousand Oaks, CA: Sage.

Cutrona, C.E., \& Russell, D. (1990). Type of social support and specific stress: Toward a theory of 
optimal matching. In I. G. Sarason, B.R. Sarason, \& G.R. Pierce (Eds.), Social support: An interactional view(pp. 319-366). New York: Wiley.

Cutrona, C. E., \& Suhr, J. A. (1992) Controllability of stressful events and satisfaction with spouse support behaviors. Communication Research 19(1), 54-174.

Cutrona, C. E., \& Suhr, J. A. (1994). Social support communication in the context of marriage: An analysis of couples' supportive interactions. In B. Burleson, T. Albrecht, \& I. Sarason (Eds.), The communication of social support: Messages, interactions, relationships, and community(pp. 113 - 135). Newbury, CA: Sage.

Drew, P. (1997) 'Open' class of repair initiators as responses to sequential sources of troubles in conversation", Journal of Pragmatics, 28(1), 69-101.

Edwards, D. (2000) Extreme case formulations: softeners, investment and doing non-literal. Research on Language and Social Interaction, 33(4), 347-373

Elgesem, D. (2002). What is special about the ethical issues in online research? Ethics and Information Technology, 4(2), 195-203.

Flicker, S., Haans, D., \& Harvey, S. (2004). Ethical Dilemmas in research on Internet Communities. Qualitative Health Research, 14(1), 124-134.

Ford, C. E. \& Mori, J. (1994) Causal markers in Japanese and English conversations: A cross linguistic study of interactional grammar, Pragmatics 4(1), 31-61. 
Frohlich, D. M., Drew, P., \& Monk, A. (1994). The management of repair in human-computer interaction. Human Computer Interaction, 9(3-4), 385-426.

Garcia, A.C. \& Jacobs, J.B. (1999). The eyes of the beholder: Understanding the turn-taking system in quasi-synchronous computer-mediated communication. Research on Language and Social Interaction, 32(4), 337-367.

Goldsmith, D. J. (2004) Communicating social support. Cambridge, UK: Cambridge. University Press,

Griffiths, F., Lindenmeyer, A., Powell, J., Lowe, P., Thorogood, M. \& Murray, E. (2006) Why are health care interventions delivered over the internet? a systematic review of the published literature. Journal of Medical Internet Research, 8(2) doi:10.2196/jmir.8.2.e10

Heritage, J. (1984) Garfinkel and ethnomethodology. Cambridge: Polity Press.

Heritage, J. (1984b). A change-of-state token and aspects of its sequential placement. In J. M. Atkinson \& J. Heritage (Eds.), Structures of social action: Studies in conversation analysis (pp. 299-345). Cambridge, UK: Cambridge University Press.

Heritage, J \& Maynard D. (Eds) (2006), Communication in Medical Care: Interactions between Primary Care Physicians and Patients. Cambridge: Cambridge University Press.

Heritage, J. \& Sefi, S. (1992) Dilemmas of Advice: Aspects of the Delivery and Reception of Advice in Interactions between Health Visitors and First Time Mothers. In P. Drew \& J. Heritage (Eds.), Talk at Work (pp.359-419) Cambridge: Cambridge University Press. 
Herring, S. C. (1999) Interactional coherence in CMC. Journal of Computer-Mediated Communication, 4(4). http://www.ascusc.org/jcmc/vol4/issue4/herring.html

Herring, S. C. (2001) Computer-mediated discourse. In D. Tannen, D. Schiffin, \& H. Hamilton (Eds.), Handbook of Discourse Analysis (pp. 612-634). Oxford: Blackwell.

Herring, S. C. (2004). Computer-mediated discourse analysis: An approach to researching online communities. In S. A. Barab, R. Kling, \& J. H. Gray, (Eds.), Designing for Virtual Communities in the Service of Learning (pp. 338-376). Cambridge: Cambridge University Press.

Hine, S. (2000). Virtual ethnography. London: Sage.

Hutchby, I., \& Wooffitt, R., (1998) Conversation Analysis. Cambridge, UK: Polity Press.

Kim, K. (1999) Phrasal Unit Boundaries and Organization of Turns and Sequences in Korean Conversation, Human Studies, 22(4): 425-46.

Lamerichs, J. \& te Molder, H. (2003). Computer-mediated communication: From a cognitive to a discursive model. New Media \& Society, 5(4), 451-473.

Miller, D. \& Slater, D. (2000). The Internet: An Ethnographic Approach. Oxford: Berg.

Núñez, F., Gálvez, A., \& Vayreda, A. (2002). La participación en un foro electrónico: Motivos, auditorios y posicionamientos. Redcientífica. 47(1) http://www.redcientifica.com/doc/doc200211290001.html

Pomerantz, A. (1986) Extreme case formulations: a way of legitimising claims. Human Studies, 9(2-3), 
Reed, D. (2001) Making conversation: sequential integrity and the local management of interaction on Internet newsgroups. Proceedings of the 34th Hawaii International Conference on System Sciences2001. http://csdl.computer.org/comp/proceedings/hicss/2001/0981/04/09814035abs.htm

Robinson J.D. \& Turner J. (2003) Impersonal, Interpersonal, and Hyperpersonal Social Support: Cancer and Older Adults. Health Communication, 15(2), 227 - 234.

Sacks, H. (1987): On the preference for agreement and contiguity in sequences in conversation. In Button, G. \& J. R. Lee (Eds.) Talk and social organization. (pp 54-69). Clevedon: Multilingual Matters.

Sacks, H (1992) Lectures on Conversation (Vols 1 and 2) Oxford: Basil Blackwell.

Sacks, H., Schegloff, E. \& Jefferson, G. (1974) A simplest systematics for the organization of turn-taking for conversation, Language 50(4): 696-735.

Schegloff, E.A. (1968) Sequencing in Conversational Openings. American Anthropologist 70(4), 10751095.

Schegloff, E. A. \& Sacks, H, (1967) Opening up closings. Semiotica, 7(2), 289-327.

Sharf, B. F. (1999). Beyond netiquette: The ethics of doing naturalistic discourse research on the Internet. In S. Jones (Ed.) Doing internet research: critical issues and methods for examining the net (pp.243-256). Thousand Oaks: Sage. 
Silverman, D (1997) Discourses of Counselling. London: Sage.

Sorjonen, M. (1996) On repeats and responses in Finnish conversation. In: E. Ochs, E. A. Schegloff, \& S.A. Thompson (Eds.) Interaction and Grammar. (pp. 277-327) Cambridge: Cambridge University Press.

Walther, J. B. \& Boyd, S. (2002). Attraction to computer-mediated social support. In C. Lin \& D. Atkin (Eds.), Communication technology and society: Audience adoption and uses (pp. 153-188). Cresskill, NJ: Hampton Press. 
Agnès Vayreda, PhD, is a lecturer in Estudis d'Humanitats i de Filologia at the Universitat Oberta de Catalunya, in Barcelona, Spain.

Charles Antaki, PhD, is Professor of Language and Social Psychology in the Department of Social Sciences, Loughborough University, Loughborough, England. 